- Original Article

\title{
Factors that Predict Smoking Cessation among Older Koreans: Based on the Korea National Health and Nutrition Examination Survey 2016-2018
}

\author{
Han Kyul Lim, Yong Soon Park*, Jeong Hyeon Kim, Jeong Hyun Kim \\ Department of Family Medicine, Hallym University Chuncheon Sacred Heart Hospital, Chuncheon, Korea
}

\begin{abstract}
Background: Tobacco smoking is associated with several diseases and deaths in older Koreans. This study aimed to evaluate the factors associated with smoking cessation in older Koreans.

Methods: We selected 579 subjects who started smoking before the age of 65 years from the Korea National Health and Nutrition Examination Survey 2016-2018. We excluded the subjects who quit smoking before the age of 65 years, and then categorized the rest of subjects into those who stopped smoking after the age of 65 years and those who are constant smokers. Multivariable logistic analysis was performed to evaluate the factors related to smoking cessation among older Koreans.

Results: Among the participants, $66.1 \%$ were persistent smokers. After multivariable analysis, the factors significantly associated with smoking cessation were as follows: being in the age group of 75-79 years (adjusted odds ratio [aOR], 4.07; 95\% confidence interval [CI], 2.12-7.83), being in the age group of 70-74 years (aOR, 3.10; 95\% CI, 1.725.61), a family history of ischemic heart disease (aOR, 3.36; 95\% CI, 1.09-10.35), and having had no cancer screening (aOR, 0.36; 95\% CI, 0.18-0.70).

Conclusion: Further efforts to identify the factors related to smoking cessation will help formulate a smoking cessation policy.
\end{abstract}

Keywords: Cigarette Smoking; Smoking Cessation; Aged; Korea National Health and Nutrition Examination Survey

Received: September 1, 2020, Revised: December 14, 2020, Accepted: December 22, 2020

${ }^{*}$ Corresponding Author: Yong Soon Park https://orcid.org/0000-0002-8926-9836

Tel: +82-33-240-5311, Fax: +82-33-240-5440, E-mail: pyongs@hallym.or.kr 


\section{INTRODUCTION}

It is well-known that smoking causes numerous diseases and increases mortality rate. Smoking increases all-cause mortality and diseasespecific mortality from cancer, cardiovascular diseases, and respiratory diseases. ${ }^{1)}$ In Korea, smoking-attributed mortality was $34.7 \%$ of the total mortality in 2012. ${ }^{2)}$ Smoking is the most common cause of cancer. ${ }^{3)}$ For these reasons, several attempts have been made to discourage smoking. After the signing of the World Health Organization Framework Convention on Tobacco Control in 2005, various smoking cessation policies resulted in a decrease in the total smoking rate in Korea. ${ }^{4)}$

Smoking cessation has several benefits in all age groups. Although some smokers have a misconception that quitting smoking may reduce the quality of life (QOL), recent studies have shown that smoking cessation improves QOL. ${ }^{5)}$ It is also well-known that quitting smoking reduces all-cause mortality and the risk of hospitalization in older adults. ${ }^{6,7)}$ Despite the benefits of smoking cessation, attempts to quit smoking among older adults are lower than those in the younger age group. ${ }^{8)}$ The results were consistent among female smokers. ${ }^{9)}$ This is probably due to nicotine dependence in old age, which is shown to be a predictor of successful cessation. . $^{10,11}$

Several studies have attempted to identify predictors of successful smoking cessation. Previous studies have shown that high nicotine dependency, low education, and being unmarried are associated with failure in smoking cessation. ${ }^{12,13)}$ Younger age also correlated with attempts to quit smoking. ${ }^{14)}$ Studies in Korea have also examined factors associated with smoking cessation and the intention to quit smoking. However, most of these studies were designed for the general population and did not show a general difference between persistent smokers and ex-smokers in old age. Therefore, we conducted this study to assess the various factors associated with smoking cessation among older Koreans.

\section{METHODS}

\section{Study Population}

This study was based on data from the seventh Korea National Health and Nutrition Examination Survey (KNHANES VII) conducted from 2016 to 2018 by the Korea Centers for Disease Control and Prevention. The survey was performed using a rolling sampling design, and the target population comprised non-institutionalized Korean civilians aged $\geq 1$ year. The sampling frame was constructed from the 2010 population and housing census, and the 2011-2014 standard declared the price of the apartments. A stratified multistage probability sampling design was used to select the household units. Among the 4,050 participants aged 65 to 79 years, we selected participants who had initiated smoking before the age of 65 years, including those who were currently smoking $(\mathrm{n}=371)$ and those who quit smoking $(\mathrm{n}=1,051)$. Participants who were currently smoking were enrolled in the "persistent smoker group". Participants who quit smoking before 65 years ( $\mathrm{n}=843)$ were excluded, and the rest were enrolled as the "ex-smoker group" $(n=208)$. A total of 579 participants were enrolled and analyzed (Figure 1). All participants of the seventh KNHANES provided informed consent, and no ethical approval from the institutional review board was required, as the KNHANES data were publicly available.

\section{Data Collection and Measurement}

We included variables such as age, sex, and socioeconomic factors, including education level, economic status, and marital status. The ages were based on the actual date of birth and divided into three groups at intervals of 5 years. The education level was classified as high school graduate or below middle school level. The participants were divided into employed and unemployed groups. Employed individuals included those who worked over 1 hour for income or 18 hours as unpaid family workers for 1 week, including temporary leave of absence. Monthly household income was divided into quintiles and grouped into the lowest, mid-low/mid/mid-high, and highest. Unmarried, separated, widowed, and divorced participants were assigned a "no

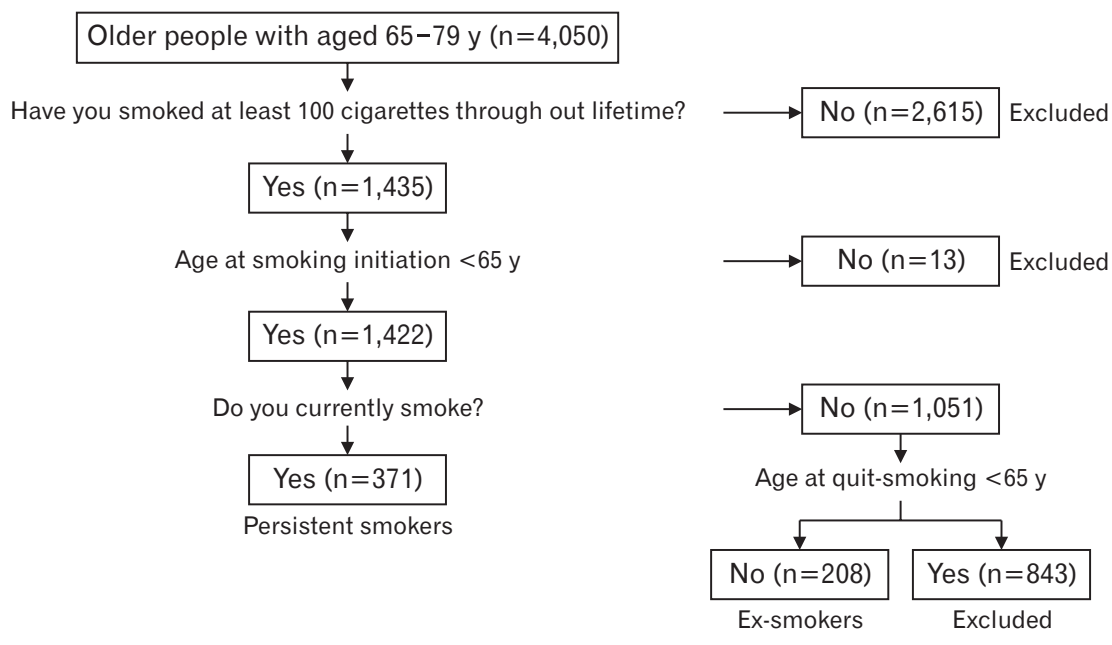

Figure 1. Process for selecting study subjects. 
spouse" status.

We also included variables related to health, including medical history, medication, family history, and stress. Medical history included past and prevailing conditions, such as stroke, ischemic heart disease (IHD), tuberculosis, asthma, chronic obstructive pulmonary disease (COPD), depression, and cancer, which were diagnosed by a doctor. Regarding participants' medication history, medications for hypertension, dyslipidemia, and diabetes were taken into account. Family history, stroke, and IHD were evaluated in the study. Stress was measured by asking the participants the following question: "How much stress do you feel in your daily life?" The options for this question were "very low", "low", "high", and "very high". Participants who responded with "high" and "very high" were included in the stress-positive group.
Health behavior-related variables include alcohol consumption, regular walking, strength exercise, health screening, and cancer screening. Alcohol consumption is classified as the consumption of alcohol by participants who do not drink or drink once a week or more. Regular walking was defined as walking more than 5 times per week for at least 30 minutes. Strength exercises were classified as exercises at least twice a week or less. Regarding health and cancer screening, the participants who had undergone screening during the last 2 years were included.

Smoking-related variables included secondhand smoking and electronic cigarette use. Secondhand smoking was assessed by asking the participants the following question: "Have you ever experienced inhaling smoke breathed out by other smokers in the workplace, home, or

Table 1. Comparisons of characteristics between participants with persistent smoking and quit-smoking after the age 65 in older Korean based on the Korea National Health and Nutrition Examination Survey VII

\begin{tabular}{|c|c|c|c|c|}
\hline Characteristic & Total $(n=579)$ & Persistent smokers $(\mathrm{n}=371)$ & Ex-smokers $(n=208)$ & P-value \\
\hline Age (y) & & & & $<0.001$ \\
\hline $75-79$ & $183(29.0)$ & $96(22.8)$ & $87(41.1)$ & \\
\hline $70-74$ & $205(33.5)$ & $118(30.0)$ & $87(40.5)$ & \\
\hline 65-69 & $191(37.4)$ & $157(47.2)$ & $34(18.4)$ & \\
\hline Sex (male) & 515 (89.5) & 327 (89.1) & $188(90.3)$ & 0.685 \\
\hline Education (smiddle school) & $365(65.6)$ & $238(68.7)$ & $127(59.4)$ & 0.048 \\
\hline Employment (no) & $325(57.9)$ & $193(53.6)$ & $132(66.1)$ & 0.008 \\
\hline Household income* & & & & 0.036 \\
\hline Lowest quintile & $137(24.5)$ & 99 (28.2) & 38 (17.5) & \\
\hline Middle & $362(61.9)$ & $224(59.9)$ & $138(65.9)$ & \\
\hline Highest quintile & 76 (13.5) & $46(12.0)$ & $30(16.6)$ & \\
\hline Spouse $\left(\right.$ no) ${ }^{\dagger}$ & $126(21.0)$ & $84(22.3)$ & $42(18.6)$ & 0.320 \\
\hline \multicolumn{5}{|l|}{ Medical history } \\
\hline Stroke & $43(8.2)$ & $30(9.3)$ & $13(6.2)$ & 0.274 \\
\hline Ischemic heart disease & $59(10.1)$ & $34(9.2)$ & $25(11.8)$ & 0.389 \\
\hline Tuberculosis & $45(7.9)$ & $28(6.6)$ & $17(10.3)$ & 0.169 \\
\hline Asthma & $26(5.0)$ & $17(5.0)$ & $9(5.1)$ & 0.965 \\
\hline Chronic obstructive pulmonary disease & $13(2.1)$ & $7(2.0)$ & $6(2.4)$ & 0.662 \\
\hline Depression & $20(3.2)$ & $14(3.2)$ & $6(3.2)$ & 0.974 \\
\hline Cancer & $31(5.2)$ & $11(3.7)$ & $20(8.0)$ & 0.071 \\
\hline \multicolumn{5}{|l|}{ Medication } \\
\hline Hypertension & $301(52.3)$ & $178(48.3)$ & $123(60.0)$ & 0.018 \\
\hline Dyslipidemia & $126(22.0)$ & $75(20.5)$ & $51(25.1)$ & 0.239 \\
\hline Diabetes & $145(24.0)$ & $89(22.0)$ & $56(27.8)$ & 0.146 \\
\hline \multicolumn{5}{|l|}{ Family history } \\
\hline Stroke & $72(12.1)$ & $50(14.0)$ & $22(8.2)$ & 0.045 \\
\hline Ischemic heart disease & $18(2.7)$ & $8(1.7)$ & $10(4.6)$ & 0.036 \\
\hline Stress (yes) & $108(18.0)$ & $75(18.8)$ & $33(16.4)$ & 0.535 \\
\hline Alcohol drink ( $\geq 2 / w k$ ) & $199(35.2)$ & $133(37.4)$ & $66(30.9)$ & 0.153 \\
\hline Regular walking $(\mathrm{no})^{\ddagger}$ & $356(64.9)$ & $224(63.7)$ & $132(67.3)$ & 0.466 \\
\hline Strength exercise ( $\leq 1 /$ wk) & $450(79.7)$ & $294(81.8)$ & $156(75.6)$ & 0.159 \\
\hline Health screening $(\mathrm{no})^{\S}$ & $177(33.7)$ & $126(36.5)$ & $51(28.3)$ & 0.073 \\
\hline Cancer screening $(\text { no })^{\S}$ & 207 (38.5) & $149(42.9)$ & $58(30.0)$ & 0.007 \\
\hline Secondhand Smoke (yes) & $126(23.6)$ & $88(25.1)$ & $38(20.8)$ & 0.318 \\
\hline Electronic cigarette (yes) & $52(8.4)$ & $41(9.5)$ & $11(6.3)$ & 0.293 \\
\hline
\end{tabular}

Values are presented as frequency (weighted \%). P-values are derived from chi-square tests for proportions. All estimates were weighted based on sample rate, response rate, and age and sex proportions of the reference population.

*Monthly household income was divided into quintiles and grouped into lowest, mid-low/mid/mid-high, and highest. †Unmarried, separated, widowed, and divorced participants were assigned a "no spouse" status. *Regular walking is defined as walking more than 5 times per week for at least 30 minutes. ${ }^{\S}$ Health and cancer screening referred to participants who had undergone screening during the last 2 years. 
public space during the last 7 days?" Regarding the use of electronic cigarettes, participants who had smoked electronic cigarettes at least once or never smoked were included.

\section{Statistical Analysis}

All estimates were weighted based on the sample rate, response rate, and the age and sex proportions of the reference population. This means that each observation in the KNHANES data was obtained by a different sampling probability. The results of the analysis of the KNHANES data are usually presented as a weighted mean or proportion and standard error. Standard error provides the precision of the estimate of the national population, which entirely relates to the aims of the KNHANES. The analyses were adjusted for the complex sample design of the survey based on the guidelines for the use of raw data from the KNHANES. Categorical data are presented as weighted proportions and standard error, and the comparison between persistent smokers and ex-smokers who stopped smoking after the age of 65 years was performed using the Rao-Scott chi-square test. Complex sample logistic regression analyses were used to identify the relationship between ex-smokers who stopped smoking after the age of 65 years and related factors in older Koreans. A multivariable analysis model was developed with ex-smokers who stopped smoking after the age of 65 years as the outcome variable and the related factors with P-values of less than 0.1 in the univariate analysis as explanatory variables. All tests were twosided, and P-values of $<0.05$ were considered to indicate statistical significance. Statistical analyses were performed using IBM SPSS Statistics for Windows ver. 24.0 (IBM Corp., Armonk, NY, USA).

\section{RESULTS}

Table 1 presents the general characteristics of the study population. Overall, $66.1 \%$ (standard error $=2.3 \%$ ) were persistent smokers, and $89.5 \%$ were male. Of the participants, $8.2 \%$ were diagnosed with stroke, $10.1 \%$ were diagnosed with IHD, 5.0\% had asthma, 2.1\% had COPD, and $5.2 \%$ had cancer. Ex-smokers who stopped smoking after the age of 65 years were significantly older than persistent smokers $(\mathrm{P}<0.001)$ and more likely to be unemployed, have a medical history of cancer, use anti-hypertensive medications, and have a family history of IHD (all $\mathrm{P}<0.1$ ). Conversely, persistent smokers were more likely than exsmokers who stopped smoking after the age of 65 years to report low education, lower income, and no health and cancer screening (all $\mathrm{P}<0.1)$.

Table 2 shows the results of the final model for the multivariable analysis with adjustment for all variables that were statistically significant in the univariable analyses (Nagelkerke $\mathrm{R}^{2}=0.194$ and $\mathrm{C}=0.706$; 95\% CI, 0.661-0.751). Being in the age group of 75-79 years (adjusted odds ratio $[\mathrm{aOR}], 4.07 ; 95 \%$ confidence interval [CI], 2.12-7.83), being in the age group 70-74 years (aOR, 3.10; 95\% CI, 1.72-5.61), family history of IHD (aOR, 3.36; 95\% CI, 1.09-10.35), and having had no cancer screening (aOR, 0.36; 95\% CI, 0.18-0.70) were significantly associated with smoking cessation in older Koreans.
Table 2. Multivariable-adjusted evaluation of the factors associated with quitting smoking after the age 65 in older Korean based on the Korea National Health and Nutrition Examination Survey VII

\begin{tabular}{|c|c|c|}
\hline Variable & Adjusted OR (95\% Cl) & P-value \\
\hline \multicolumn{3}{|l|}{ Age (y) } \\
\hline 75-79 & 4.07 (2.12-7.83) & $<0.001$ \\
\hline $70-74$ & $3.10(1.72-5.61)$ & $<0.001$ \\
\hline $65-69$ & 1 (Reference) & \\
\hline \multicolumn{3}{|l|}{ Sex } \\
\hline Male & $1.35(0.66-2.76)$ & 0.416 \\
\hline Female & 1 (Reference) & \\
\hline \multicolumn{3}{|l|}{ Education } \\
\hline$\leq$ Middle school & $0.73(0.46-1.15)$ & 0.170 \\
\hline >Middle school & 1 (Reference) & \\
\hline \multicolumn{3}{|l|}{ Household income* } \\
\hline Lowest quintile & $0.61(0.29-1.30)$ & 0.204 \\
\hline Middle & $0.94(0.48-1.85)$ & 0.854 \\
\hline Highest quintile & 1 (Reference) & \\
\hline \multicolumn{3}{|l|}{ Employment } \\
\hline No & $1.48(0.95-2.32)$ & 0.083 \\
\hline Yes & 1 (Reference) & \\
\hline \multicolumn{3}{|l|}{ Medical history: cancer } \\
\hline Yes & $1.68(0.51-5.54)$ & 0.394 \\
\hline No & 1 (Reference) & \\
\hline \multicolumn{3}{|l|}{ Medication: hypertension } \\
\hline Yes & $1.32(0.85-2.05)$ & 0.222 \\
\hline No & 1 (Reference) & \\
\hline \multicolumn{3}{|l|}{ Family history: stroke } \\
\hline Yes & $0.52(0.27-1.02)$ & 0.055 \\
\hline No & 1 (Reference) & \\
\hline \multicolumn{3}{|c|}{ Family history: ischemic heart disease } \\
\hline Yes & $3.36(1.09-10.35)$ & 0.035 \\
\hline No & 1 (Reference) & \\
\hline \multicolumn{3}{|l|}{ Health screening $^{\dagger}$} \\
\hline No & $1.54(0.78-3.04)$ & 0.218 \\
\hline Yes & 1 (Reference) & \\
\hline \multicolumn{3}{|l|}{ Cancer screening $^{\dagger}$} \\
\hline No & $0.36(0.18-0.70)$ & 0.003 \\
\hline Yes & 1 (Reference) & \\
\hline
\end{tabular}

Adjusted ORs and 95\% Cls were estimated using the multiple logistic regression analysis with adjustment for all other variables (Nagelkerke $\mathrm{R}^{2}=0.194$ and $\mathrm{C}=0.706$; $95 \% \mathrm{Cl}, 0.661-0.751)$.

$\mathrm{OR}$, odds ratio; $\mathrm{Cl}$, confidence interval.

*Monthly household income was divided into quintiles and grouped into lowest, midlow/mid/mid-high, and highest. ${ }^{+}$Health and cancer screening referred to participants who had undergone screening during the last 2 years.

\section{DISCUSSION}

In this study, we aimed to evaluate the factors associated with persistent smoking and smoking cessation after 65 years of age in Koreans aged 65-79 years. Older participants and those who had a family history of IHD were more likely to quit smoking, whereas participants who had not undergone cancer screening during the past 2 years tended to continue smoking.

Previous studies have shown that old age is correlated with successful smoking cessation. A previous study on older female smokers showed that they were highly motivated to quit smoking. ${ }^{15)}$ The results 
were similar to those of studies on male smokers and patients who visited public health centers in Korea. ${ }^{16)}$ Similar results were obtained in this study: participants in the age groups of 75-79 and 70-74 years were more likely to quit smoking than the younger group. However, this could be the result of a length bias. It is well-known that persistent smoking is associated with all-cause mortality and smoking-related disease mortality. ${ }^{17)}$ In addition, previous studies have shown that the risk of mortality is reduced after smoking cessation. ${ }^{18)}$ Therefore, the results of this study indicate that older age groups are more likely to quit smoking, as smoking may be the cause of death in older persistent smokers.

In previous studies, other socioeconomic factors, such as education level, marital status, and economic status, were predictors of successful smoking cessation. In a previous study in Korea, education level was a predictor of successful smoking cessation in male smokers. ${ }^{16)}$ In older men, the smoking rate was high when they were single and their economic status was unsatisfactory. Older women also had a higher smoking rate when their economic status was poor. ${ }^{19)}$ A study in Taiwan showed that marital breakdown is associated with higher smoking rates, and that socially active participants displayed successful smoking cessation. ${ }^{20)}$ However, in this study, there was no significant association between smoking cessation and socioeconomic factors. Education level and economic status were not significantly different between persistent smokers and ex-smokers who stopped smoking after the age of 65 years. Marital status was also not a significant factor in this study.

Smoking-related cardiovascular diseases, respiratory diseases, and cancer are known to be associated with smoking cessation. Patients who were diagnosed with stroke reduced the number of cigarettes smoked daily and successfully quit smoking without any support, such as a smoking cessation clinic. ${ }^{21)}$ Patients with severe IHD, depending on its severity, were likely to quit smoking. ${ }^{22,23)}$ The intention to quit smoking was also associated with a history of IHD. ${ }^{24)}$ However, there were no significant associations with the participants' medical history in this study. The reason may be the low rate of diagnosed diseases; only $8.2 \%, 10.1 \%$, and $5.2 \%$ were diagnosed with stroke, IHD, and cancer, respectively. However, we found that family history of IHD was associated with smoking cessation after the age of 65 years. Participants with a family history of IHD were associated were likely to cease smoking after the age of 65 (OR, 3.36; 95\% CI, 1.09-10.35), and no similar relationship was shown in previous studies.

In this study, after multivariable adjustment, participants who did not undergo cancer screening during the last 2 years were more likely to remain persistent smokers. It appears that taking interest in good health leads to quitting smoking, ${ }^{25)}$ and participants who undergo regular cancer screening may be interested in good health. Another previous study showed that health screening increases interest in health and attempts to quit smoking. ${ }^{26)}$ However, regular health screening was not significantly associated with smoking cessation after the age of 65 years in this study.

This study has several limitations. First, since it is a cross-sectional study, it does not show a cause-and-effect relationship. Second, we could not use factors directly associated with smoking, such as nicotine dependency, because this was a secondary analysis. Third, the sample size was relatively small because we focused on persistent smokers and ex-smokers who stopped smoking between 65 and 79 years. It was also difficult to obtain results with participants who were diagnosed with smoking-related diseases. Fourth, although old age was associated with smoking cessation, there may have been a bias due to the high mortality associated with smoking.

Despite these limitations, this study has several strengths. First, this study was based on data from the KNHANES, which represents the general population of Korea. Second, research on the differences between persistent smokers and ex-smokers among older adults is limited. Understanding the different characteristics will be beneficial when formulating a smoking cessation policy.

In conclusion, this study found that several older adults in Korea are persistent smokers, and some factors contribute to the continuation or cessation of smoking. Not getting regular cancer screening was associated with persistent smoking, whereas older age and a family history of IHD were associated with smoking cessation. Efforts toward smoking cessation are crucial in the outpatient setting and smoking cessation clinics, especially when patients are not undergoing regular cancer screening, which may help reduce the smoking rate in older adults. ${ }^{27)}$ Unlike previous studies, there was no significant differences between participants' education levels, economic statuses, marital statuses, and medical conditions. Further research is needed to clarify the differences between persistent and ex-smokers.

\section{CONFLICT OF INTEREST}

No potential conflict of interest relevant to this article was reported.

\section{ORCID}

Han Kyul Lim: https://orcid.org/0000-0002-0886-8061 Yong Soon Park: https://orcid.org/0000-0002-8926-9836 Jeong Hyeon Kim: https://orcid.org/0000-0002-8889-4437 Jeong Hyun Kim: https://orcid.org/0000-0003-2848-0774

\section{REFERENCES}

1. Vie GA, Wootton RE, Bjorngaard JH, Asvold BO, Taylor AE, Gabrielsen $\mathrm{ME}$, et al. The effect of smoking intensity on all-cause and cause-specific mortality: a Mendelian randomization analysis. Int J Epidemiol 2019;48:1438-46.

2. Jung KJ, Yun YD, Baek SJ, Jee SH, Kim IS. Smoking-attributable mortality among Korean adults, 2012. J Korea Soc Health Inform Stat 2013; 38:36-48.

3. Park YC, Yoon MS. Toxicological mechanisms in smoking-induced cancer: why is smoking evaluated as one of the strongest risk-factors for cancer? J Korean Soc Res Nicotine Tob 2011;2:8-22.

4. Choi EJ. Tobacco cessation policy indicators and their policy implica- 
tions. Health Welf Policy Forum 2017;(246):22-31.

5. Bloom EL, Minami H, Brown RA, Strong DR, Riebe D, Abrantes AM. Quality of life after quitting smoking and initiating aerobic exercise. Psychol Health Med 2017;22:1127-35.

6. Nash SH, Liao LM, Harris TB, Freedman ND. Cigarette smoking and mortality in adults aged 70 years and older: results from the NIHAARP Cohort. Am J Prev Med 2017;52:276-83.

7. Tran B, Falster MO, Douglas K, Blyth F, Jorm LR. Smoking and potentially preventable hospitalisation: the benefit of smoking cessation in older ages. Drug Alcohol Depend 2015;150:85-91.

8. Kahende JW, Malarcher AM, Teplinskaya A, Asman KJ. Quit attempt correlates among smokers by race/ethnicity. Int J Environ Res Public Health 2011;8:3871-88.

9. Morabia A, Costanza MC, Bernstein MS, Rielle JC. Ages at initiation of cigarette smoking and quit attempts among women: a generation effect. Am J Public Health 2002;92:71-4.

10. Hall SM, Humfleet GL, Gorecki JA, Munoz RF, Reus VI, Prochaska JJ. Older versus younger treatment-seeking smokers: differences in smoking behavior, drug and alcohol use, and psychosocial and physical functioning. Nicotine Tob Res 2008;10:463-70.

11. Gunay T, Pekel O, Simsek H, Sahan C, Soysal A, Kilinc O, et al. Smoking habits and cessation success: what differs among adults and elderly? Saudi Med J 2014;35:585-91.

12. Lee CW, Kahende J. Factors associated with successful smoking cessation in the United States, 2000. Am J Public Health 2007;97:1503-9.

13. Cohen-Mansfield J. Predictors of smoking cessation in old-old age. Nicotine Tob Res 2016;18:1675-9.

14. Lim KH, Heng PP, Nik Mohamed MH, Teh CH, Mohd Yusoff MF, Ling JM, et al. Prevalence and factors associated with attempts to quit and smoking cessation in Malaysia. Asia Pac J Public Health 2019;31(7_ suppl):22S-31S.

15. Weaver KE, Snively BM, Hogan P, Josephs K, Johnson KC, Coday M, et al. Predictors of continued smoking and interest in cessation among older female smokers. J Aging Health 2018;30:624-40.

16. Kim JS, Kang SJ, Kim DJ, Choi IY, Choi BS. Success factors of new enrollees at smoking cessation clinics in the nationwide public health centers in Korea based on gender differences. Public Health Res 2018; 44:17-30.
17. Taghizadeh N, Vonk JM, Boezen HM. Lifetime smoking history and cause-specific mortality in a cohort study with 43 years of follow-up. PLoS One 2016;11:e0153310.

18. Akter S, Nakagawa T, Honda T, Yamamoto S, Kuwahara K, Okazaki H, et al. Smoking, smoking cessation, and risk of mortality in a Japanese working population: Japan Epidemiology Collaboration on Occupational Health Study. Circ J 2018;82:3005-12.

19. Beak DH, Hwang BD, Moon HJ, Yoon HJ, Back YD, Lee SK. Smoking status and the related factors in the rural elderly. J Agric Med Community Health 2008;33:243-54.

20. Lindstrom M, Giordano GN. Changes in social capital and cigarette smoking behavior over time: a population-based panel study of temporal relationships. Nicotine Tob Res 2016;18:2106-14.

21. Kang MS, Yoo SM, Kim JW, Kim KN, Lee SY, Kim JJ, et al. The change of smoking rates before and after hospital admission following diagnosis of ischemic stroke. J Korean Soc Res Nicotine Tob 2011;2:97-103.

22. Ota A, Yasuda N, Kawai K, Tanioka K, Doi Y, Ohara H, et al. Smoking cessation after discharge among Japanese patients with established ischemic heart disease: a prospective cohort study. Acta Med Okayama 2008;62:151-7.

23. Hansen HH, Vammen B, Jensen MK. Smoking cessation in patients with stable or unstable ischemic heart disease. Ugeskr Laeger 1999; 161:3659-62.

24. Lee I, Park YS, Kim JH, Han SH. Factors associated with the intention to quit smoking in elderly Korean men: the Korea National Health and Nutrition Examination Survey 2010-2015. Korean J Fam Med 2020;41: $237-42$.

25. Shin KO, Choi KS. The comparison of health and nutrient intakes between male smokers and non-smokers. Korean J Food Nutr 2013;26: 713-24.

26. Lee JY, Jun HJ, Kang M, Park AR, Oh DE, Choi YH, et al. Effectiveness of anti-smoking interventions after general medical examination in a health promotion center-based smoking cessation settings: experience of a single clinic in Korea. J Korean Soc Res Nicotine Tob 2012;3: 19-26.

27. Song TM. Changes in smoking rates of male adults in Korea and smoking cessation policy: focus on smoking cessation clinics. Health Welf Policy Forum 2011;(173):55-63. 